\title{
Avaliação de contratos em agroindústrias processadoras de tomate em Goiás
}

\author{
Paulo Eterno Venâncio Assunção* \\ Alcido Elenor Wander ${ }^{* * *}$
}

\section{Resumo}

Este artigo tem o objetivo de analisar, sob a ótica da Nova Economia Institucional, os contratos da tomaticultura em Morrinhos, Goiás. O referencial teórico adotado fornece os conceitos de custos de transação e de estruturas de governança. Os dados utilizados são provenientes dos contratos referentes ao fornecimento de matéria-prima de três indústrias de processamento situadas em Morrinhos. Observou-se que os contratos de fornecimento constituem um importante instrumento, tanto para as indústrias processadoras, que podem contar com a produção constante e em padrões previamente especificados, quanto para os produtores rurais que buscam na agroindústria a segurança de comercialização da sua produção. Os contratos de fornecimento podem ser considerados de média especificidade de ativos, com transação frequente e reduzida incerteza.

Palavras-chave: Nova economia institucional. Contratos. Atributos das transações. Tomaticultura.

* Engenheiro Agrônomo, Mestrando do Programa de Pós-Graduação em Agronegócio da Universidade Federal de Goiás. E-mail: paulo_eterno05@hotmail.com

** Engenheiro-agrônomo, Doutor em Economia Agrícola, pesquisador da Embrapa Arroz e Feijão. E-mail: alcido.wander@embrapa.br

http://dx.doi.org/10.5335/rtee.v20i42.4478

Submissão: 25/08/2013. Aceite: 30/06/2014. 


\section{Introdução}

Na relação de compra e venda entre produtores rurais e indústria processadora, essa ação é mediada por meios de contratos de fornecimentos de produção. Tais contratos são uma modalidade de organização da produção, a qual serve como alternativa para as empresas, estando entre a verticalização da produção e os mercados abertos (DIAS, 1999).

A verticalização por parte da indústria processadora não se apresenta como uma opção viável, pois os custos fixos envolvidos com esse processo de organização da produção torna a ação inviável. Em relação ao mercado aberto, essa verticalização colocaria a indústria processadora à mercê das oscilações dos preços e das quantidades produzidas de matéria prima, assim como da qualidade dos produtos fornecidos, tornando a incerteza do suprimento de suas necessidades de processamento um problema.

Os contratos nas atividades agrícolas desempenham um papel importante na alocação dos riscos financeiros referentes à atividade. Com os contratos, os produtores diminuem os riscos referentes à fase de comercialização da sua produção e passam a ter um mercado certo para essa fase. A agroindústria encontra meios de controlar a qualidade de sua matéria-prima, pois, com o contrato, torna-se possível a exigência de condições mínimas de qualidade de produção e condução da cultura. A agroindústria também encontra meios de programar sua fase de processamento, pois, com os contratos há a garantia de fornecimento da matéria-prima.

A estrutura de governança adotada pela agroindústria processadora de tomate é a contratual. Por meio de contratos, a indústria fornece assistência técnica, financia a produção e, em alguns casos, provê, também, mudas de plantas de tomate para o início da produção. Os produtores, em contrapartida, assumem a responsabilidade de cuidar de todo o processo produtivo, da aquisição de equipamento necessário, da mão de obra e dos cuidados dispensados para a produção de frutos com qualidade.

Assim, o presente trabalho tem como objetivo geral analisar os contratos de produção de tomate industrial firmados entre as indústrias processadoras no Sul do estado de Goiás e os produtores rurais fornecedores de matéria-prima. Os objetivos específicos foram analisar: a) averiguar a frequência com que as negociações ocorrem; b) analisar as especificidades que esses contratos podem apresentar; c) ponderar as incertezas referentes à comercialização do tomate industrial entre produtor e agroindústria; e d) avaliar as estruturas do contrato firmando entre os agentes da cadeia. 
O problema de pesquisa a ser investigado é: quais são as principais características da estrutura contratual vigente entre a agroindústria de tomate e os produtores. Evidenciaram-se as particularidades dos contratos de cada uma das empresas estudadas, de acordo com o arcabouço teórico da Nova Economia Institucional (NEI).

\section{Referencial teórico}

\subsection{Nova economia institucional}

A nova economia institucional (NEI) teve início com a publicação de Ronald Coase, em 1937, denominada The nature of the firm. A principal questão apontada no trabalho se referia aos custos de transação. Nessa investigação a firma deixa de ser analisada como uma função de produção e passa a ser vista como uma organização de agentes econômicos e um nexo de contratos.

No trabalho desenvolvido por Coase (1937), observou-se que as transações do sistema econômico eram isentas de custos e que, basicamente, eram duas as formas de custos: aquelas que se referiam à coleta de informações e as referentes à negociação e ao estabelecimento de contratos. Os custos eram gerados por todos os agentes econômicos e não apenas pelos ligados à produção, referindo-se, assim, aos bancos, aos advogados, aos corretores, como geradores de custos de transação (FARINA et al., 1997).

O enfoque da análise desenvolvida por Coase destaca as formas de coordenação entre o mercado e a firma, não negando a importância das formas intermediárias de coordenação. $\mathrm{O}$ mercado e a firma concorrem para terem a função comum de coordenar a atividade econômica, com isso, eles coexistem dentro da atividade.

Nesse ponto surge a necessidade de fazer a distinção entre os custos de produção dos demais custos vinculados à tecnologia e ao relacionamento dos agentes envolvidos. Tal ação recebeu a designação de custos de transação, que podem ser definidos em quatro níveis: o primeiro nível relacionado com os custos de construção e negociação dos contratos; o segundo envolve os custos em medir e monitorar os direitos de propriedade existentes no contrato. Nesse nível, são incorporados os custos de observação dos contratos ao longo do tempo e o desempenho desses, avaliando quais atendem às expectativas das partes que fizeram a transação (JOSKOW, 1985). O terceiro nível engloba os custos de manter e fazer executar os contratos internos e externos da firma. O quarto e último nível relaciona-se com 
os custos de adaptação que os agentes sofrem com as mudanças (FARINA, 1999; WILLIAMSON, 2002; PEREIRA et al., 2008).

No entanto, os custos de transação não são facilmente mensuráveis, devido ao fato de estarem relacionados principalmente com as atitudes e/ou comportamento das partes envolvidas nas negociações, com seus atributos comportamentais (racionalidade limitada e oportunismo), que podem ocorrer tanto pré como pós-contrato (PEREIRA et al., 2008; ROCHA JÚNIOR, 2008; FRANCO et al., 2011).

Para Williamson (1975), a NEI empenhou-se em atribuir dimensões às transações, fornecendo elementos que permitissem a identificação de ação oportunista por partes dos agentes envolvidos na negociação. $\mathrm{O}$ autor ainda descreve $\mathrm{o}$ ambiente microanalítico das propriedades da estrutura de governança das transações de forma que os custos de transação são relevantes para essa teoria.

Na discussão do ambiente macroanalítico, em que as transações são desenvolvidas, quatro variáveis influenciam diretamente nos custos de transação (NORHT, 1994), a saber:

- custo de quantificação dos atributos do bem ou do serviço: avalia não apenas as dimensões físicas, mas também a dos direitos de propriedade envolvidos na transação. Nesse caso, um exemplo simples, e bem utilizado, é o do automóvel, que muitas pessoas escolhem por terem determinada cor, desempenho, potência, mas qualquer que seja a opção, a finalidade do bem é transportar;

- tamanho de mercado: pondera se as transações são pessoais (com parentes, amigos) ou impessoais (desconhecidos), nesse caso, não há nada que impeça as pessoas de levar vantagem sobre as outras;

- cumprimento das obrigações assumidas: verificar a evolução do sistema jurídico, fiscalizador e imparcial, fundamental para o desenvolvimento de sistema contratual complexo e eficiente; e

- atitudes ideológicas e percepções: busca saber como as pessoas veem as normas do jogo (instituições) e de que forma agem frente às transações e regras.

Farina (1999) ressalta que a NEI é uma extensão da Organização Industrial que insere o ambiente institucional e as variáveis transacionais, caracterizando eprocurando identificar qual a melhor forma de organização de firmas e de mercados, das transações econômicas com a melhor alocação de recursos.

Pereira et al. (2008) e Franco (2008) destacam que existem quatro pressupostos fundamentais que precisam ser considerados. Ao analisar as organizações sob a ótica da NEI são as que seguem: 
- a existência de custos na utilização do sistema de preços, tanto nas negociações efetuadas via contratos externos, quanto nas realizadas internamente na firma;

- as transações acontecem em um ambiente institucional estruturado, as instituições são importantes ao influir nos custos de transação, e o ambiente institucional afeta o processo de transferência dos direitos de propriedade;

- o oportunismo dos agentes é outro pressuposto importante, refere-se ao comportamento das pessoas que agem de forma a beneficiar a si mesma; o oportunismo pode ocorrer antes do contrato (ex-ante), chamado também de seleção adversa, ou após o contrato (ex-post), denominado risco moral; ambos ocorrem por assimetria de informação; e

- a racionalidade limitada relaciona-se ao comportamento dos agentes que não conseguem desenvolver de forma plena sua capacidade cognitiva, agem de forma racional, mas limitadamente.

Para Farina et al. (1997) e Williamson (1979, 1981, 2002), os custos de transação ocorrem porque os agentes econômicos envolvidos possuem racionalidade limitada e são oportunistas (o que recebe a denominação de pressupostos comportamentais), ademais, existem as incertezas ambientais, isso determina que os contratos sejam sempre incompletos.

Para Williamson $(1979,1981)$, a racionalidade limitada relaciona-se ao fato de os agentes atuarem de forma racional, mas limitadamente, com a intenção de conseguir os maiores benefícios ou lucros para sua empresa. Pereira et al. (2008) e Franco et al. (2011) ressalvam que a obtenção de informações e de processamento dessas empresas é limitada e custosa, isso impossibilita a previsão de todos os eventos e as possibilidades futuras. Com isso, os contratos serão sempre incompletos.

O oportunismo relaciona-se à ação dos indivíduos, o que se dá de forma ética, sempre visando obter benefício próprio. Esse comportamento pode ocorrer de duas formas: ex-ante ou ex-post.

$\mathrm{O}$ oportunismo ex-ante (antes da transação), nominado em alguns casos como seleção adversa, ocorre quando o vendedor tenta convencer o comprador de que o produto oferecido é de qualidade. Porém, tanto o vendedor, quanto o comprador podem possuir informações privilegiadas do produto, tornando a negociação injusta para uma das partes. O exemplo mais utilizado é o do mercado de automóveis usados: o vendedor, geralmente, possui informações do veículo (acidente no passado) que não passa ao comprador.

O oportunismo ex-post (ou moral hazard) se refere ao fato de um dos agentes possuir uma informação privada, possibilitando a esse agente tirar proveito após 
a assinatura do contrato, prejudicando a contraparte, o que pode ocorrer por informação ou ação oculta. Um exemplo bastante usado é o do seguro do automóvel: o segurado é consciente de que age de forma perigosa ao volante, mas não repassa, intencionalmente, tal informação à seguradora, buscando, com isso, obter vantagens no valor da parcela do seguro contratado.

Os pressupostos relatados devem ser considerados no momento em que se realiza uma transação, pois explicam o porquê de realizar qualquer tipo de procedimento ex-ante. Os contratos podem não cobrir perfeitamente todas as lacunas regidas em uma transação, porque o poder de previsão e de cálculo das pessoas não atende de forma plena, e a conduta delas não pode ser considerada (WILLIAMSON, 1981).

\subsection{Atributos das transações}

Além dos pressupostos comportamentais, existem os atributos das transações, que são a frequência, a incerteza e a especificidade dos ativos.

Para Farina et al. (1997), a frequência está relacionada com a repetição e a intensidade com que a transação ocorre no tempo, referindo-se a dois aspectos importantes nas transações: a redução de custos de monitoramento e a construção de reputação dos agentes envolvidos. Como a transação tende a ter continuidade, a ação oportunista é desestimulada sob pena de ruptura da relação.

Franco et al. (2011) definem incerteza como desconhecimento dos eventos futuros devido à informação assimétrica e incompleta e aos problemas inerentes aos ambientes e a suas complexidades em que os agentes atuam.

A especificidade dos ativos está relacionada aos ativos que não podem ser reempregados em outra atividade de produção, a não ser que haja a perda de valor, ocorrendo os custos irrecuperáveis (FARINA et al., 1997). Para os autores, essa dimensão das transações pode ser subdivida, como mostrado a seguir:

- especificidade locacional: relacionada à localização das empresas ou das firmas, por exemplo, as áreas de produção de tomate; especificidade física: relacionada às características do produto, que determinam que esse não pode ser utilizado em outra função, por exemplo, matéria-prima com características específicas com relação à pureza, à textura e à composição química ou a equipamentos para produção de determinado produto;

- especificidade de ativos humanos: refere-se ao capital humano empregado na atividade, como mão de obra especializada; 
- especificidade de ativos dedicados: ocorre apenas de forma bilateral, uma firma produz um artigo específico para determinada empresa, e o investimento realizado nessa produção não pode ser empregado em outras;

- especificidade de marca: refere-se ao capital de determinada empresa, relevante especialmente no caso de franquias; e

- especificidade temporal: significativo nos produtos do agronegócio por serem perecíveis e dependentes de curto tempo para processamento sob pena de se ter perda de matéria prima.

É importante que haja a caracterização dessas dimensões (incerteza, frequência e especificidade dos ativos), visando à minimização dos custos com a utilização de estruturas de governança que auxiliem nesse processo.

\subsection{Contratos}

Para Marques (2000), os contratos são uma obrigação, legalmente exigível, de entrega ou de recebimento de determinada quantidade e qualidade de mercadoria, a preço previamente ajustado entre as partes. Utilizando dessa ferramenta, os agentes econômicos transacionam, fazendo trocas de mercadorias, prestando serviços, gerando renda, consumo e produção.

Segundo Zylbersztajn e Sztajn (2005), o contrato é uma maneira de coordenação das transações conduzindo a promoção de incentivos para os agentes atuarem de maneira coordenada no momento da produção, permitindo um planejamento de longo prazo de ambas as partes. Os autores ainda destacam, que os contratos possuem custos relacionados à construção, à implementação, ao monitoramento $\mathrm{e}$ à solução de disputas advindas do não cumprimento do referido contrato.

Fiani (2002) destaca que podem existir quatro tipos de contratos:

- contratos que caracterizam, no presente, certo desempenho no futuro: não é flexível, indicado apenas para transações simples, em que incerteza e complexidade não estejam presentes;

- contratos que especificam no presente determinado desempenho futuro, com cláusulas condicionais: indicado quando há interesse em manter um vínculo entre vendedor e comprador, devido aos ativos possuírem alta especificidade. Quanto maior a complexidade da transação torna-se mais difícil elaborar esse contrato, a racionalidade limitada impede a antecipação de todas as circunstâncias futuras; 
- contratos de curta duração, apenas quando há necessidade de realizar a transação: as ofertas são feitas em mercado spot (à vista), cada comprador adquire o que deseja e quando lhe convém. Nesse caso, o objeto da transação deve ser homogêneo, não importando quem seja o vendedor ou o comprador;

- contratos estabelecidos no presente, dando direito de selecionar, futuramente, uma performance específica em um conjunto de performances estipulado anteriormente: chamado ainda de relação de autoridade. Não é necessário antecipar todas as circunstâncias futuras, nem recontratar sucessivamente. Esse contrato refere-se, principalmente, aos contratos de trabalho de longa duração.

Os contratos podem ser classificados em clássicos, neoclássicos e relacionais (WILLIAMSON, 1979). Os clássicos relacionam-se aos mercados em competição perfeita, nos quais ocorrem transações em período definido, com transferência de informações entre as partes e ajustes via mercado, em que as dimensões são plenamente definidas. O contrato clássico é apenas um referencial teórico, pois os contratos são sempre incompletos e de correção continuada.

Para Pereira et al. (2008) e Franco et al. (2011), os contratos neoclássicos são utilizados, quando as transações tendem a se estender a longo prazo e a variável incerteza é relevante. Não há como prever todas as formas de contingência que podem ocorrer ao longo do tempo em que for estabelecido o contrato. Com isso, são necessárias constantes adaptações no momento em que ocorrem as contingências, cabendo às partes o ato de negociação. Em alguns casos, para resolver as disputas, faz-se necessária, a presença de uma terceira parte, a qual avalia o desempenho estipulado pelo contrato no momento posterior à assinatura, o que ocorre, geralmente, em corte judicial (ZYLBERSZTAJN; SZTAJN, 2005).

Os contratos relacionais servem como alternativa contratual, quando a duração e a complexidade dos contratos são expressivas. As transações caracterizadas por esse tipo contratual são os de longo prazo. Sendo assim, os contratos são eminentemente incompletos, e as estruturas de governança caminham no sentido de hierarquizar os processos, internalizando as transações na empresa (PEREIRA et al., 2008; FRANCO et al., 2011).

Os contratos são muito comuns na agricultura, sejam de prestação de serviços, de fornecimento de insumos e de entrega da produção. Zylbersztajn (2005) destaca que os agricultores organizam-se, horizontalmente, (coordenação horizontal), em especial de forma cooperativa, visando ganhar economias de escala e de rede, ampliando a capacidade de coordenação com as indústrias processadoras, bem como adicionar valor de forma seletiva. 


\section{Metodologia}

\subsection{Natureza da pesquisa}

A metodologia adotada para investigação empírica do trabalho se baseia no enfoque metodológico conhecido como "método de pesquisa rápida" (rapid assessment, quick appraisal ou rapid appraisal). O foco principal desse método de pesquisa, como destacado por Souza Filho e Silva (2007), é buscar a captação de informações necessárias à realização de investigações por meio de entrevistas com agentes-chave na cadeia produtiva estudada, tais como associações, sindicatos, diretores de empresas, instituições, entre outros componentes da cadeia.

Franco et al. (2011) destacam que o método de pesquisa rápida é bastante útil, quando utilizado na análise de cadeias produtivas, principalmente quando os recursos e o tempo são fatores escassos, impedindo a realização de avaliações formais. As informações podem ser obtidas por meio informal ou formal, ou por uma combinação dos dois.

Usaid (1996) ressalta que o Método de Pesquisa Rápida é recomendado para a avaliação do desempenho de sistemas e se mostra apropriado nos casos em que: a) as informações descritivas e qualitativas são suficientes para a tomada de decisão; b) é necessária a compreensão das relações de causa e efeito que afetam o comportamento do sistema; c) é preciso uma interpretação dos dados levantados: d) o objetivo está em gerar sugestões e recomendações; e) é necessário desenvolver melhores questionamentos, hipóteses e suposições para posterior elaboração de um estudo formal, fundamentado em análises estatísticas.

\subsection{Fonte de dados}

Há a valorização de informações obtidas em fontes secundárias, que precisam ser consideradas na etapa inicial da pesquisa. Em seguida, são realizadas entrevistas com poucos agentes-chave da cadeia estudada, os quais são entendidos como aqueles que têm representatividade na cadeia, incluindo empresas do ramo, associações e órgãos representantes dessa cadeia, órgãos vinculados ao poder público. Para que haja o ganho de tempo, as questões contidas no questionário devem abranger apenas os aspectos que não podem ser respondidos por fontes secundárias de dados. 
As informações primárias contidas no presente trabalho foram coletadas por meio de entrevistas junto a uma amostra não probabilística de agentes da cadeia produtiva do tomate para processamento industrial na cidade Morrinhos, Goiás. Foram analisados os contratos da tomaticultura firmados entre os produtores e três empresas de processamento e industrialização, denominadas A, B e C.

\subsection{Análise dos dados}

O período de desenvolvimento da análise foi entre novembro de 2012 e janeiro de 2013. Os contratos foram analisados quanto à sua característica, com base no referencial teórico proposto pela NEI, nos atributos das transações (frequência, incerteza e especificidade dos ativos), bem como nas relações contratuais (contratos neoclássicos ou relacionais).

\section{Resultados e discussão}

$\mathrm{Na}$ região estudada, no momento em que os produtores rurais fazem o contrato para a produção de tomate industrial, eles começaram a receber assistência técnica em suas áreas de produção. Em alguns casos, os produtores recebem subsídios para produção do tomate. $\mathrm{O}$ pagamento pela produção é feito no momento da entrega das caixas de tomate à indústria processadora.

A vantagem que se apresenta para os produtores na utilização desse sistema é a garantia de mercado para sua produção e, também, a transferência do risco para a agroindústria. Em anos passados, alguns produtores vinculados à agroindústria C, enfrentavam o problema de a agroindústria não conseguir escoar sua produção para a indústria processadora, por falta de caminhões e, às vezes, por falta de capacidade de processamento da indústria.

Isso causava prejuízos para os produtores, que não recebiam pela produção que ficava no campo. Os produtores ficavam vinculados ao contrato, de maneira que não podiam procurar outra forma de comercialização, o que causou a diminuição de fornecimento de tomate para a agroindústria C. O problema foi resolvido com o aumento da capacidade de processamento da indústria e com uma cláusula no contrato, que permite aos produtores procurarem outra forma de comercializar sua produção, buscando diminuir ao máximo as perdas.

Em algumas cadeias coordenadas pelos contratos, o processo de especialização se torna caminho certo para o setor de produção, visando maior eficiência na produção da matéria-prima, mesmo não sendo um elemento existente nos contratos. 
As análises dos contratos descritas a seguir, pelas especificidades dos ativos (locacional, físicos, temporal, dedicados), pela frequência e pela incerteza, foram separadas por tópicos com vistas a melhorar a compreensão dos resultados.

\subsection{Análise dos contratos pela especificidade dos ativos}

Dias (2005) destaca que uma variedade de tomate mais específica ao processamento industrial acaba resultando em um ativo altamente específico, restando para o produtor, depois do processo produtivo, poucas opções do que fazer com $o$ produto.

A especificidade locacional se refere às necessidades dos produtores integrados terem suas áreas de produção localizadas próximas às indústrias processadoras. Nos contratos estudados não foram encontradas cláusulas relacionadas a essa especificidade, mesmo sendo um ponto importante na tomaticultura.

$\mathrm{Na}$ tomaticultura, essa especificidade é importante, pois tem-se uma exigência do fator custo de transporte da produção, ligado à indústria processadora. Grande parte das propriedades rurais estudadas apresentam estradas de acesso não pavimentadas e, geralmente, em péssimo estado de conservação. Dias (2005) destaca que o tomate, por ser altamente perecível, apresenta uma elevada especificidade locacional. Quando produzido em uma variedade industrial, amadurece no ponto do processamento, o que torna a chegada à processadora uma maneira crucial para evitar perdas.

Para a indústria, quanto mais tempo o tomate passa dentro dos caminhões, maiores são as perdas organolépticas do tomate, como destacado por Gameiro et al. (2007). Os autores ainda ressaltam que uma quantidade considerável das perdas no momento do processamento do tomate está relacionada às perdas no transporte da produção para a indústria. As perdas foram quantificadas em $2,1 \%$ do peso bruto da produção, perfazendo uma perda na ordem de $\mathrm{R} \$ 1$ milhão por safra (GAMEIRO et al., 2007).

$\mathrm{Na}$ tomaticultura, os investimentos de ativos físicos estão envolvidos com a aquisição de tecnologia por parte dos produtores, basicamente a aquisição de sistema de irrigação, seja irrigação por pivô central, seja por aspersores. As empresas processadoras financiam os projetos de montagem dos sistemas de irrigação (projeto de aquisição do sistema, outorga d'água e montagem do sistema). Os produtores realizam o pagamento, conforme a entrega de sua produção, sendo descontadas pequenas porcentagens. 
A manutenção do sistema é de responsabilidade dos produtores, troca de peças, regulagem do sistema, revistas periódicas etc. Todas as empresas apresentam uma cláusula em relação a essa especificidade, pois os produtores podem explorar a produção em momentos oportunos para empresa, fazendo com que cada área de produção tenha seu ciclo de produção diferente, evitando congestionamentos no momento da atividade da agroindústria.

Em relação à especificidade de ativos dedicados, eles ocorrem quando o fornecedor realiza investimentos, visando atender à demanda de um cliente específico, pois os ativos adquiridos nesse momento visam a suprir aquele demandante. Não foi observada a realização desse tipo de investimento por parte dos tomaticultores.

A aquisição de sistema de irrigação, que é o grande ativo para entrada na atividade, pode ser utilizado na exploração de outras culturas que não o tomate. Caso haja o desalinho entre a indústria processadora contratante e o agricultor contratado, o segundo pode executar contratos de fornecimento de sua produção com outra processadora, sem ter que fazer outro investimento, ou mesmo mudar de cultura de exploração.

Quando os produtores tem um sistema de produção mais tecnificado, e optam pela aquisição de transplantadeiras e colheitadeiras, acabam adquirindo ativos físicos altamente específicos, pois tais ativos de mecanização agrícola não podem ser empregados em outras atividades de produção agrícola, tendo o seu uso restrito à atividade da tomaticultura.

\subsection{Análise dos contratos pela incerteza}

A incerteza refere-se à imprevisibilidade das atitudes posteriores dos agentes econômicos. No momento da colheita dos frutos, esta incerteza é minimizada, pois os contratos firmados possuem cláusulas específicas para esse momento.

As cláusulas fornecem a descrição em relação ao fornecimento de mudas pela indústria processadora, esse fornecimento acontece na presença do produtor quando ocorre vistoria ou visita da área de produção para monitoramento de doenças e para rotação de culturas nas áreas de produção. Nessas cláusulas, tem-se claro o compromisso de os produtores venderem apenas para única indústria processadora, mantendo certo cuidado com doenças e pragas nas áreas de produção, não cultivando plantas que sejam hospedeiras alternativas de insetos e de doenças que possam atacar a cultura do tomate, são alguns dos preceitos em relação aos cuidados no processo produtivo.

Teoria e Evidência Econômica - Ano 20, n. 42, p. 91-109, jan./jun. 2014 
Um dos cuidados mais observados em relação à indústria processadora refere-se ao período de carência dos defensivos agrícolas utilizados na condução da lavoura (período no qual os produtos deixam de ter um efeito ativo sobre e dentro dos frutos). $\mathrm{O}$ produtor que não respeita o período de carência exigido pela indústria corre o risco de ter seu contrato cancelado e de responder por não observância de cláusulas do contrato, como citado por Assunção (2012).

\subsection{Análise dos contratos pela frequência}

Grande parte dos contratos firmados nos sistemas de produção agropecuários é de tempo indeterminado, desde que o produtor e o contratante cumpram todas as normas estipuladas previamente. Essa frequência de relacionamento é garantida para a empresa, que pode contar com um número certo de produtores e com toneladas de tomate para o processamento. E o produtor rural pode contar com a segurança da venda de sua produção.

Seguindo esse critério, o produtor de tomate tem a tomaticultura como uma opção de renda contínua durante $o$ ano, e desenvolve segurança em relação ao seu processo produtivo, garantido assistência técnica, financiamentos e mercado para sua produção.

\subsection{Análise dos contratos de fornecimento para a produção de tomate}

$\mathrm{Na}$ execução dos contratos de entrega da produção de tomate, os produtores recebem assistência técnica e financiamento para a aquisição de insumos necessários para a produção. Em relação aos preços, as empresas praticam preços semelhantes na compra da tonelada de tomate.

Os processos de acerto dos preços seguem o mesmo critério para as três processadoras. Os preços são negociados de antemão com os produtores, assim como destacado por Assunção (2012) e Dias (2005), os preços se constituem num dos principais itens dos contratos.

Os preços são fixados em relação ao custo de produção encontrado nas safras anteriores, procurando um permeio em que os produtores não tenham prejuízos com a atividade em relação ao preço pago pela produção e seu custo. Além disso, busca-se, também, que as indústrias processadoras não paguem preços muito acima do praticado para o tomate industrial no mercado. 
Outro item de grande importância observado em ambos os contratos, é o relacionado à área de produção. Procura-se fazer a estimação do volume de produto por hectare, considerando dois pontos, a produtividade média da lavoura na região e o histórico de produção do agricultor. Isso faz com que as indústrias assegurem o suprimento contínuo de matérias-primas de acordo com sua capacidade instalada de processamento (DIAS, 2005). E os produtores podem fazer a estimação do valor obtido com a cultura do tomateiro, podendo planejar a renda derivada da atividade. Assunção (2012) e Dias (2005) destacam que essa relação contratual com a agroindústria é uma forma de redução dos riscos e da volatilidade dos preços, o que caracteriza os mercados agrícolas.

Em relação aos contratos, individualmente detalhados no Quadro 1, os contratos da empresa "A" mostram-se superficiais em muitas questões, e não contemplam várias circunstâncias, detalhes ou problemas corriqueiros, bem como não preveem a devida solução. Não há, assim como nos outros contratos, especificidade locacional, tão importante nessa atividade. Não há, ainda, a especificação de características dos tomates entregues (nível de maturação, grau Brix e período de carência de aplicações de defensivos nos frutos).

Quadro 1: Detalhamento dos contratos de fornecimento para a produção de tomate.

\begin{tabular}{|c|c|c|c|}
\hline Item & Empresa A & Empresa B & Empresa C \\
\hline $\begin{array}{l}\text { Qualidade dos fru- } \\
\text { tos e prazo de en- } \\
\text { trega }\end{array}$ & Sem cláusulas específicas & $\begin{array}{l}\text { Em ótimas condições, res- } \\
\text { peitando o período de ca- } \\
\text { rência }\end{array}$ & $\begin{array}{l}\text { Em ótimas condições, res- } \\
\text { peitando o período de ca- } \\
\text { rência }\end{array}$ \\
\hline $\begin{array}{l}\text { Quantidade forne- } \\
\text { cida é dependente }\end{array}$ & $\begin{array}{l}\text { Da área de produção, do } \\
\text { histórico da produtividade e } \\
\text { do produtor, da necessida- } \\
\text { de da processadora }\end{array}$ & $\begin{array}{l}\text { Da área de produção, do } \\
\text { histórico da produtividade e } \\
\text { do produtor, da necessida- } \\
\text { de da processadora }\end{array}$ & $\begin{array}{l}\text { Da área de produção, do } \\
\text { histórico da produtividade e } \\
\text { do produtor, da necessida- } \\
\text { de da processadora }\end{array}$ \\
\hline $\begin{array}{l}\text { Fornecimento de } \\
\text { insumos e assis- } \\
\text { tência técnica }\end{array}$ & $\begin{array}{l}\text { Financiamento da produção } \\
\text { e assistência técnica }\end{array}$ & $\begin{array}{l}\text { Financiamento da produção } \\
\text { e assistência técnica }\end{array}$ & $\begin{array}{l}\text { Financiamento da produção } \\
\text { e assistência técnica }\end{array}$ \\
\hline $\begin{array}{l}\text { Preço da tonela- } \\
\text { da de tomate }\end{array}$ & $\begin{array}{l}\text { Fixado conforme os balan- } \\
\text { ços feitos em conformidade } \\
\text { entre empresa e produtor }\end{array}$ & $\begin{array}{l}\text { Fixado conforme os balan- } \\
\text { ços feitos em conformidade } \\
\text { entre empresa e produtor }\end{array}$ & $\begin{array}{l}\text { Fixado conforme os balan- } \\
\text { ços feitos em conformidade } \\
\text { entre empresa e produtor }\end{array}$ \\
\hline $\begin{array}{l}\text { Prazo de vigência } \\
\text { do contrato }\end{array}$ & $\begin{array}{l}\text { Tempo indeterminado, pas- } \\
\text { sível de quebra, caso seja } \\
\text { necessário. Renovado anu- } \\
\text { almente com novos termos, } \\
\text { se necessário }\end{array}$ & $\begin{array}{l}\text { Tempo indeterminado, pas- } \\
\text { sível de quebra, caso ne- } \\
\text { cessário. Renovado anual- } \\
\text { mente com novos termos, } \\
\text { se necessário }\end{array}$ & $\begin{array}{l}\text { Tempo indeterminado, pas- } \\
\text { sível de quebra, caso ne- } \\
\text { cessário. Renovado anual- } \\
\text { mente com novos termos, } \\
\text { se necessário }\end{array}$ \\
\hline $\begin{array}{l}\text { Detalhamento dos } \\
\text { frutos }\end{array}$ & $\begin{array}{l}\text { Colhidos conforme a matu- } \\
\text { ridade e a necessidade da } \\
\text { empresa }\end{array}$ & $\begin{array}{l}\text { Colhidos conforme a matu- } \\
\text { ridade e a necessidade da } \\
\text { empresa }\end{array}$ & $\begin{array}{l}\text { Colhidos conforme a matu- } \\
\text { ridade e a necessidade da } \\
\text { empresa }\end{array}$ \\
\hline Visitas de inspeção & Não detalhado no contrato & Não detalhado no contrato & Exigência em contrato. \\
\hline $\begin{array}{l}\text { Mão de obra qua- } \\
\text { lificada e especia- } \\
\text { lizada }\end{array}$ & $\begin{array}{l}\text { Não há exigência em con- } \\
\text { trato }\end{array}$ & $\begin{array}{l}\text { Não há exigência em con- } \\
\text { trato }\end{array}$ & $\begin{array}{l}\text { Há uma cláusula sobre o } \\
\text { treinamento de mão de obra } \\
\text { e a obrigação de uso de EPI }\end{array}$ \\
\hline
\end{tabular}


O prazo de vigência do contrato não é citado, mas há cláusulas sobre a possibilidade de rescisão, por parte da empresa, para o caso em que os produtores não tenham cumprido as normas técnicas de produção, ambiental sanitária das lavouras e dos condutores da cultura. A rescisão por parte dos produtores, diz respeito ao não cumprimento de cláusulas de financiamentos da produção, da assistência técnica e dos preços acordados da tonelada produzida.

A empresa "B" possui contrato mais detalhado, prevendo diversas circunstâncias específicas, inclusive o rompimento do contrato por não cumprimento de ambas as partes das cláusulas previstas. Tal documento descreve com detalhes as características dos tomates entregues. A empresa financia a produção, fazendo empréstimo para a aquisição de mudas e de adubação, fornecendo também a assistência técnica necessária em todos os períodos da produção (preparo do solo, plantio, condução da cultura, colheita e pós-colheita).

$\mathrm{O}$ contrato vigora por tempo indeterminado, enquanto forem cumpridas todas as exigências técnicas, ambiental e de sanidade das lavouras e dos condutores da cultura. Os preços são combinados previamente, assim como no contrato da empresa "A".

O contrato da empresa "C" é o mais detalhado dos três contratos. Exige formação específica da mão de obra utilizada na condução da cultura, assim como utilização de EPI (Equipamento de Proteção Individual) em todos os processos produtivos.

Há a especificação detalhada das circunstâncias de rompimento do contrato, assim como as sanções legais que a parte não cumpridora pode sofrer, com cláusulas claras de fácil interpretação. Há também a descrição de detalhe acerca das características dos tomates entregues, assim como cláusulas de penalidades para o não cumprimento de tais preceitos.

A empresa fornece assistência técnica em todos os períodos do processo produtivo, porém, assim como as outras duas processadoras, não apresenta nenhuma cláusula referente à especificidade locacional da produção, mas é a única das três que assegura logística de escoamento da produção para o tomaticultor no momento da colheita, pois possuem frota própria para essa atividade.

O contrato vigora, assim como nas outras empresas, por tempo indeterminado, enquanto forem cumpridas todas as exigências técnicas, ambientais e de sanidade das lavouras e dos condutores da cultura. O preço também é pré-fixado. É o único contrato que apresentou uma cláusula exigindo a trafegabilidade nas áreas de produção e a inspeções por técnicos da empresa para observação das condições sanitárias sem aviso prévio. 


\section{Considerações finais}

Os contratos de integração analisados no trabalho podem ser considerados de média especificidade de ativos, com as transações acontecendo de maneira frequente e com reduzida incerteza de negociação. A especificidade de ativos foi considerada média, pois, para que haja uma exploração tecnificada da tomaticultura é necessária a aquisição de equipamentos específicos, como colheitadeiras e transplantadeiras. Porém, a mão de obra utilizada não precisa ser especializada para a exploração, mesmo que em um dos contratos seja encontrada uma cláusula com exigência do treinamento dessa mão de obra.

$\mathrm{O}$ que poderia ser feito em relação às especificidades de equipamentos, seria a utilização das políticas do governo federal que investem na aquisição de máquinas agrícolas para a modernização das cadeias produtivas nacionais por meio do Programa de Aceleração do Crescimento (PAC 2), contando com linhas de créditos específicas para aquisição dessas máquinas.

A frequência da entrega é considerada recorrente, devido aos investimentos iniciais realizados pelos produtores rurais (aquisição de equipamentos de irrigação, quando necessários e máquinas especificas para a atividade), assim como da empresa (no planejamento da produção, dos períodos de processamento, entre outros).

A incerteza é considerada nula, tanto para as empresas quanto para os produtores. As empresas financiam a produção, a aquisição de insumos e realizam o apoio técnico necessário, podendo influenciar de maneira direta na qualidade dos frutos recebidos. Os produtores, por sua vez, não precisam recorrer ao mercado para procurar por compradores, pois com o sistema de contrato de fornecimento, eles têm conhecimento de datas planejadas pela indústria, e dos valores que devem receber pela tonelada de tomate.

Em relação aos contratos, apenas o contrato da empresa "C" pode ser considerado completo, pois traz o detalhamento de diversas partes da produção, considerando várias circunstâncias que podem ocorrer durante o processo no campo, detalhando as obrigações da empresa e do produtor, destacando-se que são de fácil leitura e compreensão. As empresas "A" e "B" precisariam detalhar melhor seus contratos, inserindo cláusulas mais bem elaboradas, com descrições detalhadas do processo, dos frutos, para que possam ser feitas exigências do produtor em relação à qualidade do produto e do processo de produção. 


\title{
Evaluation of tomato production contracts in Goiás state
}

\begin{abstract}
This article aims to examine contracts of tomato production in Morrinhos, Goiás, from the perspective of New Institutional Economics. The theoretical reference provides the concepts of transaction costs and governance structures. The data were derived from contracts relating to the supply of raw material to of three processing industries located in Morrinhos, Goiás. It was observed that supply contracts have been an important tool for both processing industry, which can count on the constant and in previously specified production patterns, as for farmers, who have in agroindustry the marketing guarantee of their production. The supply contracts can be considered as of intermediate asset specificity, high transaction frequency and low uncertainty.
\end{abstract}

Keywords: New institutional economics. Contracts. Attributes of the transactions. Tomato production.

\section{Evaluación de contractos de la industrias procesadoras de tomate en Goias}

\section{Resumen}

Este estudio tiene como objetivo analizar los contratos de producción de tomate en Morrinhos, Goiás, desde la perspectiva de la Nueva Economía Institucional. El enfoque teórico proporciona los conceptos de costos de transacción y las estructuras de gobernancia. Los datos utilizados eran de los contratos relativos al suministro de materias primas a partir de tres industrias de transformación de tomate ubicadas en Morrinhos. Se observó que los contratos de suministro han sido una herramienta importante, tanto para la industria de transformación, que pueden contar con la producción constante y estándares especificados de antemano, y para los agricultores, que tienen la seguridad de la comercialización agroindustrial de sus productos. Los contratos de suministro se pueden considerar la especificidad del activo medio, y la reducción de la incertidumbre con las transacciones frecuentes.

Palabras clave: Nueva economía institucional. Contratos. Atributos de las transacciones. Producción de tomate. 


\section{Referências}

ASSUNÇÃO, P. E. V. Análise da relação contratual entre tomaticultores de Morrinhos, GO, e a indústria processadora. In: CONGRESSO DA SOCIEDADE BRASILEIRA DE ECONOMIA E SOCIOLOGIA RURAL, 50, 2012, Vitrória. Anais... Brasília: SOBER, 2012. p. 1-12. Meio eletrônico. Disponível em: <http://icongresso.itarget.com.br/useradm/anais/?clt=ser.2>. Acesso em: 12 nov. 2012.

CARVALHO, J. F.; PAGLIUCA, L. G. Tomate, um mercado que não para crescer globalmente. Hortifruti Brasil, Junho, 2007.

DIAS, D. R. Coordenação contratual na agroindústria de tomate. Cadernos de Debates. Campinas: Nepa/Unicamp, v. 7, 1999.

DIAS, D.R. Relações contratuais na agroindústria em Goiás: o caso dos produtores de tomate. In: CONGRESSO DA SOCIEDADE BRASILEIRA DE ECONOMIA E SOCIOLOGIA RURAL, 43., 2005, Ribeirão Preto, Anais... Brasília: SOBER, 2005, meio eletrônico. Disponível em: < http:// www.sober.org.br/palestra/2/790.pdf>. Acesso em: 27 jan. 2013.

FARINA, E. M. M. Q. Competitividade e coordenação de sistemas agroindustriais: um ensaio conceitual. Revista Gestão e Produção, São Carlos, v. 6, n. 3, p. 147-161, dez. 1999.

FARINA, E. M. M. Q.; AZEVEDO, P. F.; SAES, M. S. M. Competitividade: mercado, Estado e Organização. São Paulo: Singular, 1997. 286 p.

FIANI, R. A teoria dos custos de transação. In: KUPFER, D.; HASENCLEVER, L. Economia industrial. Rio de Janeiro: Campus, 2002. p. 276-306.

FRANCO, C. et al. Análise dos contratos na avicultura de corte em Mato Grosso sob a ótica de Nova Economia Institucional (NEI). Revista de Economia e Agronegócio, Viçosa, v. 9, n. 2, p. 149186. 2011.

GAMEIRO, A. H. et al. Estimativa de perdas no suprimento de tomates para processamento industrial no Estado de Goiás. Informações Econômicas, São Paulo, v. 37, n. 7, p. 7-16, jul. 2007.

JOSKOW, P. L. Price adjustment in long-term contracts: the case of coal. The Journal of Law and Economics, London, v. 1, p. 33, Apr. 1985.

MARQUES, P. V. Mercados futuros e de operações agropecuários. In: ZYLBERSZTAJN, D.; NEVES, M. F. Economia e gestão dos negócios agroalimentares: indústria de alimentos, indústria de insumos, produção agropecuária. São Paulo: Pioneira, 2000. p. 211-234.

PEREIRA, S. M. et al. Análise de contratos na suinocultura sob a óptica da Nova Economia Institucional. In: CONGRESSO DA SOCIEDADE BRASILEIRA DE ECONOMIA E SOCIOLOGIA RURAL, 46, 2008, Rio Branco. Anais... Brasília: SOBER, 2008, meio eletrônico. Disponível em: <http://www.sober.org.br/palestra/9/534.pdf>. Acesso em: 28 jan. 2013.

SOUZA FILHO, H. M.; SILVA, C. A. Guidelines for rapid appraisal of agrifood chain performance in developing countries. Roma: Food and Agriculture Organization of The United Nations, 2007.

USAID. Performance monitoring and evaluation tips - USAID Center for development information and evaluation: Using rapid appraisal methods. 1996. Disponível em: <http://www.path.org/ publications/list.php>. Acesso em: 30 jan. 2013. 
WILLIAMSON, O. E. Transaction-cost economics: the governance of contractual relations. Journal of Law and Economics, Chicago, v. 22, n. 2, p. 233-261, out. 1979.

The modern corporation: origins, evolution and attributes. Journal of Economic Literature, Stanford, v. 19, n. 4, p. 1537-1568, dez. 1981.

The theory of the firm as governance structure: from choice of contract. Journal of Economic Perspectives, v. 16, n. 3, p. 171-195, 2002.

ZYLBERSZTAJN, D. Papel dos contratos na coordenação agroindustrial: um olhar além dos mercados. Aula Magna de abertura, CONGRESSO BRASILEIRO DE ECONOMIA E SOCIOLOGIA RURAL, XLIII. Anais... Ribeirão Preto - SP, 2005.

ZYLBERSZTAJN, D.; SZTAJN, R. Direito e economia: análise econômica do direito e das organizações. Rio de Janeiro: Elsevier, 2005. 315 p. 